\title{
Impact of Droughts on Winter Wheat Yield in Different Growth Stages during 2001-2016 in Eastern China
}

\author{
Huiqian $\mathrm{Yu}^{1,2,3} \cdot$ Qiang Zhang $^{1,2,3} \cdot$ Peng Sun $^{4} \cdot$ Changqing Song ${ }^{1,2,3}$
}

Published online: 20 September 2018

(C) The Author(s) 2018

\begin{abstract}
Remote sensing can provide near real-time and dynamic monitoring of drought. The drought severity index (DSI), based on the normalized difference vegetation index (NDVI) and evapotranspiration/potential evapotranspiration (ET/PET), has been used for drought monitoring. This study examined the relationship between the DSI and winter wheat yield for prefecture-level cities in five provinces of eastern China during 2001-2016. We first analyzed the spatial and temporal distribution of droughts in the study area. Then the correlation coefficient between drought-affected area and detrended yield of winter wheat was quantified and the impact of droughts of different intensities on winter wheat yield during different growth stages was investigated. The results show that incipient drought during the wintering period has no significant impact on the yield of winter wheat, while moderate drought in the same period can reduce yield. Drought affects winter wheat yield significantly during the flowering and filling stages. Droughts of higher intensity have more significant negative effects on the yield of winter wheat. Monitoring of droughts and irrigation is critical
\end{abstract}

Qiang Zhang

zhangq68@bnu.edu.cn

1 Key Laboratory of Environmental Change and Natural Disaster, Ministry of Education, Beijing Normal University, Beijing 100875, China

2 Academy of Disaster Reduction and Emergency Management, Ministry of Emergency Management and Ministry of Education, Beijing Normal University, Beijing 100875, China

3 Faculty of Geographical Science, Beijing Normal University, Beijing 100875, China

4 College of Territorial Resource and Tourism, Anhui Normal University, Anhui 241002, China during these periods to ensure normal yield of winter wheat. This study has important practical implications for the planning of irrigation and food security.

Keywords China - Drought intensity · Drought severity index $\cdot$ Winter wheat crop yields

\section{Introduction}

In the backdrop of global warming, extreme meteorological and hydrological events-such as heat waves, droughts, and floods-have been amplifying persistently in terms of frequency and intensity (Salinger et al. 2000; Seneviratne et al. 2012). Intensifying extreme weather events have remarkable impacts on the stability and sustainable development of economy and human society (Rosenzweig et al. 2001; Battisti and Naylor 2009; Chen et al. 2010; Coumou and Rahmstorf 2012; Powell and Reinhard 2016) and pose a range of challenges to human adaptation to climate change, especially with respect to food security (Devereux 2007; Douglas 2009; Godfray et al. 2011; Lobell et al. 2011; Beddington et al. 2012). Among the numerous meteorological and hydrological extreme events, droughts are less understood but often disastrous due to their higher occurrence frequency, long duration, and widespread impacts across larger spatial scales. Droughts often trigger serious shortages of drinking water and soil moisture, and even ecological and environmental degradation.

Droughts have the greatest impact on agricultural production. A prolonged and severe drought will result in a significant decrease in the production of crops and serious issues of food supply and food security (Park et al. 2016). By studying the impact of extreme events on crop yields 
during 1964-2007, Lesk et al. (2016) found that droughts and extremely high temperatures often led to sharply reduced crop yields by as much as $9-10 \%$ globally. From September 2009 to March 2010, a rare autumn-winter spring drought in southwestern China directly affected more than 69 million people and 6.6 million hectares of crops, and resulted in a reduction of 4.362 billion kilograms of grain, with a direct economic loss of more than RMB 400 billion yuan (China Meteorological Administration 2011; MWRC 2011). The impact of drought on agricultural production has raised widespread societal concerns (Qin et al. 2014; Zhang, Gu et al. 2015; Zhang, Sun et al. 2015; Sun, Zhang, Cheng et al. 2017).

Many drought indices have been proposed to reflect the spatial and temporal distribution and evolution of droughts. Some are based on precipitation-the Palmer Drought Severity Index (Palmer 1965), the Standardized Precipitation Index (McKee et al. 1993), and the Standardized Precipitation Evapotranspiration Index (Vicente-Serrano et al. 2010) all have been widely used in drought monitoring. However, the main variables of such indices are precipitation and evapotranspiration, which cannot reflect the impacts of drought on crop growth but are more suitable for meteorological drought monitoring. Moreover, the occurrence and development of drought is planar, while these drought indices use site-based observational rainfall data, which cannot effectively reflect the development process of drought in the two-dimensional plane.

With the development of technology in remote sensing, its strength in wide coverage and near real-time monitoring was increasingly corroborated. Many studies use the normalized difference vegetation index (NDVI) to conduct vegetation monitoring in different regions of China to quantify the relationship between vegetation and hydrothermal changes and to estimate crop yields (Song et al. 2011; Zhao et al. 2012; Li and Chen 2014). The NDVI can make up for the deficiency of insufficient coverage of site data and can reflect the effects of drought from the perspective of the vegetation, which is more suitable for agricultural drought monitoring. Evapotranspiration and vegetation factors can both be taken into consideration in calculating the DSI, which can be more accurate in reflecting agricultural drought.

Previous drought research in China has mainly focused on the spatial and temporal characteristics of droughts in terms of their causes, influencing factors, and related monitoring and prediction practices (Guo et al. 2017; Sun, Zhang, Wen et al. 2017; Zhang et al. 2018). Relevant studies that have addressed the impacts of floods and droughts on agricultural production have mainly focused on the quantification of the relations between the frequency and intensity of droughts and floods and disaster-affected and damaged croplands (Zhang, Gu et al. 2015; Sun,
Zhang, Cheng et al. 2017). However, agricultural production includes different types of crops. Each crop has a different response to water stress, and the water requirements of each crop are different during different growth and development stages. Therefore, it is theoretically and practically significant to analyze the specific impacts of droughts of different intensity on crop production during specific crop growing and developing periods. Few reports have addressed these scientific issues. Answers to these questions can greatly help to plan agricultural irrigation based on the different water requirements of crops during different phenology periods and safeguard agricultural production to the largest degree. This study differentiates the effects of droughts on the yield of winter wheat from the perspectives of drought intensity and occurrence timing in the main winter wheat producing areas in China-Anhui, Hebei, Henan, Jiangsu, and Shandong Provinces.

\section{Study Region}

China is an agricultural country with the largest population in the world and food security is important for its social stability (Ghose 2014). Winter wheat is one of the main grain crops in the country. The sown area of winter wheat accounted for about $15 \%$ of the total sown area of crops in 2015 and $21 \%$ of China's total crop production (NBSC 2016).

The study region $\left(29^{\circ} 41^{\prime} \mathrm{N}-42^{\circ} 40^{\prime} \mathrm{N}, \quad 110^{\circ} 21^{\prime} \mathrm{E}-\right.$ $122^{\circ} 43^{\prime} \mathrm{E}$ ) is dominated by plains topographically, with a cropland area of up to 32 million hectares, accounting for $26.69 \%$ of the total arable land area in China (Fig. 1). The winter wheat yield of this region accounted for $75.79 \%$ of the national total winter wheat yield in 2015 , making the study region the largest winter wheat producing area in China (NBSC 2016). The region has a mainly semi-humid climate with an annual rainfall amount of $400-800 \mathrm{~mm}$. Affected by the monsoon climate, large seasonal precipitation anomalies can be observed across the region. Recent decades have witnessed increasing demand for water resources due to a growing population and the rapid development of agriculture. But the study region is also dominated by a higher frequency of droughts (Qi et al. 2011). In the past 50 years, approximately $30-40$ regional droughts have occurred in the study region. The highest occurrence frequency of droughts was observed in the North China Plain, with 40-45 drought events (Zhang et al. 2016; Sun, Zhang, Wen et al. 2017). About $79 \%$ of the droughts occurred during the growing periods of wheatdrought was one of the dominant natural hazards that affected wheat yields (Farhangfar et al. 2015). Frequent droughts with high intensity and long duration often lead to yield decrease or even absolute failure of winter wheat and 


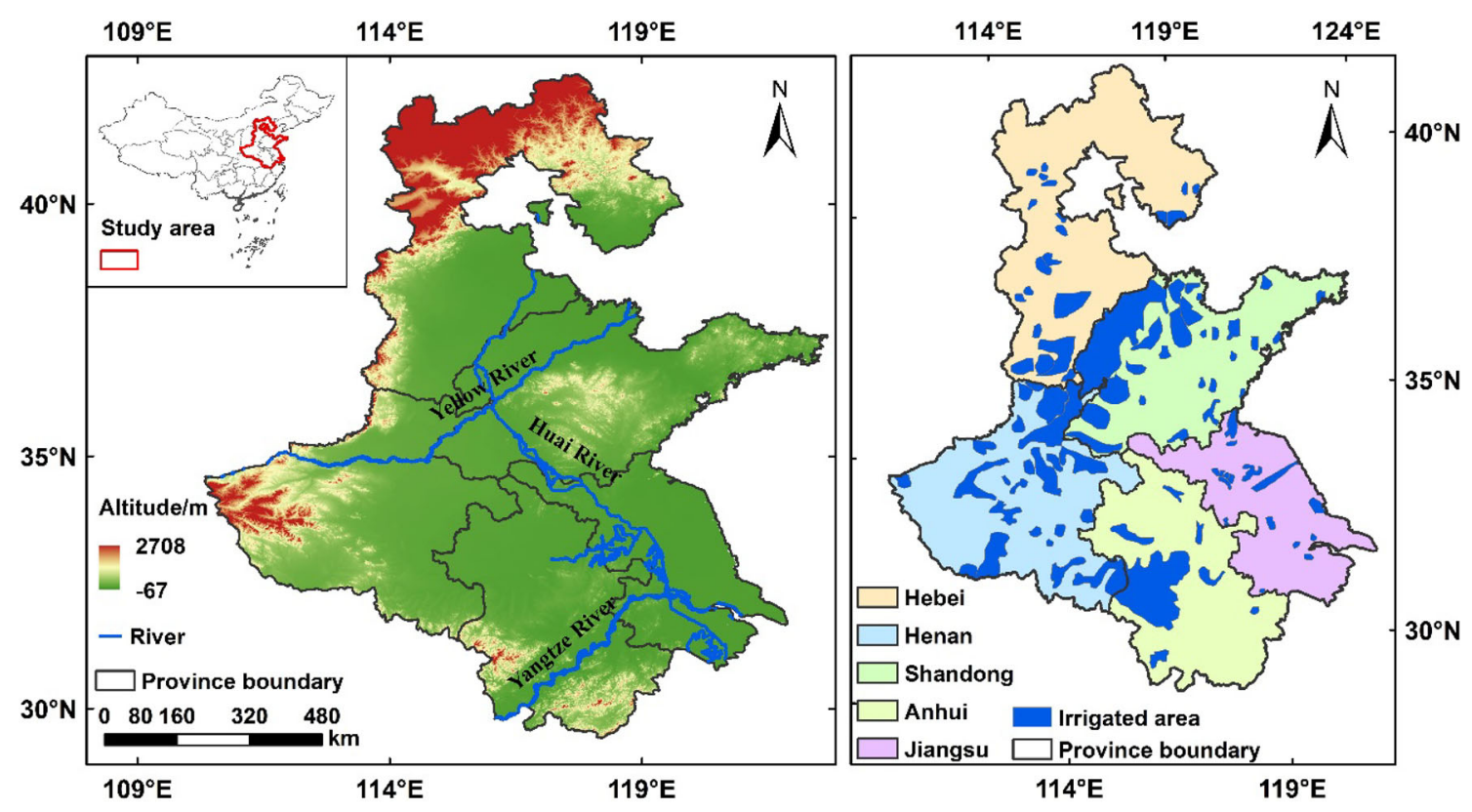

Fig. 1 Topography, water system, and irrigation areas of the five-province study region in China

seriously affect the grain supply in China. Therefore it is of paramount theoretical and practical significance to investigate the impact of droughts on the yield of winter wheat in China.

\section{Data and Methods}

The data analyzed in this study are remote sensing and disaster-induced crop loss data. The research methods include HP filter method for calculating the detrended yields and Pearson correlation coefficient analysis for showing the impact of droughts on winter wheat yields in different growth stages.

\subsection{Data}

Remote sensing data are often used to monitor vegetation growth due to their large observation area, long observation time, and near real-time monitoring performance (Peters et al. 2002; Abduwasit et al. 2007). The remote sensing data for the computation of the drought severity index (DSI) include MOD09A1 V006 and MOD16A2 V006 downloaded from the Land Processes Distributed Active Archive Center (LP DAAC) ${ }^{1}$ with a temporal resolution of 8 days and a spatial resolution of $500 \mathrm{~m}$. The MOD09A1 data set covers the period from 1 February 2000 to the present, of which data for the 166th and 177th days are missing in 2001; the MOD16A2 data set covers the period

\footnotetext{
${ }^{1} \mathrm{http} / / /$ lpdaac.usgs.gov/.
}

from 1 January 2001 to the present, of which data for the 177th day in 2001 and 10 days of data in 2008 are missing. Considering the continuity and consistency of the data, images from 2001 to 2016 were analyzed in this study, and a few missing data were interpolated using long-term mean values. After the preprocessing procedure on the MOD09A1 dataset, the NDVI for each grid can be obtained as:

$\mathrm{NDVI}=\frac{R_{\mathrm{nir}}-R_{\mathrm{red}}}{R_{\mathrm{nir}}+R_{\mathrm{red}}}$

where $R_{\text {nir }}$ is the near infrared reflectivity and $R_{\text {red }}$ is the infrared reflectivity. The total winter wheat yield for the five provinces of the study region during 2001-2016 was retrieved from the China Statistical Yearbook 2002-2017 released by the National Bureau of Statistics. ${ }^{2}$ The winter wheat yields of most prefecture-level cities in the study area were obtained from the statistical yearbooks of Hebei, Henan, Shandong, and Anhui Provinces, but the data for the prefecture-level cities of Jiangsu Province were collected from the statistical yearbooks of each individual city. Data of the exact growing and developing periods for winter wheat were obtained from the agricultural database of the Division of Plantation Management of the Ministry of Agriculture, China. ${ }^{3}$ Growing and developing of winter wheat is divided into different stages, such as seeding, sprouting, tillering, overwintering, green, jointing, heading, flowering, filling, and maturity, and the specific classification is shown in Table 1 .

\footnotetext{
2 http://www.stats.gov.cn/tjsj/ndsj/.

3 http://www.zzys.moa.gov.cn/.
} 
Table 1 Growing and developing periods for winter wheat in five provinces

\begin{tabular}{|c|c|c|c|c|c|c|}
\hline Month & $\begin{array}{l}\text { Ten } \\
\text { days }\end{array}$ & Anhui & Hebei & Henan & Jiangsu & Shandong \\
\hline \multirow[t]{3}{*}{ October } & First & Seeding & Seeding & Seeding & Seeding & Seeding \\
\hline & Middle & Sprouting & Sprouting & Sprouting & $\begin{array}{c}\text { Seeding and } \\
\text { sprouting }\end{array}$ & Sprouting \\
\hline & Last & Sprouting & $\begin{array}{l}\text { Sprouting and } \\
\text { tillering }\end{array}$ & $\begin{array}{l}\text { Sprouting and } \\
\text { tillering }\end{array}$ & Sprouting & $\begin{array}{l}\text { Sprouting and } \\
\text { tillering }\end{array}$ \\
\hline \multirow[t]{3}{*}{ November } & First & $\begin{array}{l}\text { Sprouting and } \\
\text { tillering }\end{array}$ & $\begin{array}{l}\text { Sprouting and } \\
\text { tillering }\end{array}$ & $\begin{array}{l}\text { Sprouting and } \\
\text { tillering }\end{array}$ & $\begin{array}{l}\text { Sprouting and } \\
\text { tillering }\end{array}$ & $\begin{array}{l}\text { Sprouting and } \\
\text { tillering }\end{array}$ \\
\hline & Middle & $\begin{array}{l}\text { Sprouting and } \\
\text { tillering }\end{array}$ & Tillering & Tillering & $\begin{array}{l}\text { Sprouting and } \\
\text { tillering }\end{array}$ & Tillering \\
\hline & Last & $\begin{array}{l}\text { Sprouting and } \\
\text { tillering }\end{array}$ & Tillering & Tillering & $\begin{array}{l}\text { Sprouting and } \\
\text { tillering }\end{array}$ & Tillering \\
\hline \multirow[t]{3}{*}{ December } & First & Tillering & Tillering & Tillering & Tillering & Overwintering \\
\hline & Middle & Tillering & Overwintering & Tillering & Tillering & Overwintering \\
\hline & Last & Tillering & Overwintering & Overwintering & Tillering & Overwintering \\
\hline \multirow[t]{3}{*}{ January } & First & Overwintering & Overwintering & Overwintering & Overwintering & Overwintering \\
\hline & Middle & Overwintering & Overwintering & Overwintering & Overwintering & Overwintering \\
\hline & Last & Overwintering & Overwintering & Overwintering & Overwintering & Overwintering \\
\hline \multirow[t]{3}{*}{ February } & First & Overwintering & Overwintering & Overwintering & Overwintering & Overwintering \\
\hline & Middle & Green & Overwintering & Overwintering & Overwintering & Overwintering \\
\hline & Last & Green & Overwintering & Green & Green & Green \\
\hline \multirow[t]{3}{*}{ March } & First & Jointing & Green & Green & Green and jointing & Green \\
\hline & Middle & Jointing & Green & Jointing & Jointing & Green \\
\hline & Last & Jointing and heading & Green & Jointing and heading & Jointing & Jointing \\
\hline \multirow[t]{3}{*}{ April } & First & $\begin{array}{l}\text { Heading and } \\
\text { flowering }\end{array}$ & Jointing & Jointing and heading & Jointing and heading & Jointing and heading \\
\hline & Middle & $\begin{array}{l}\text { Heading and } \\
\text { flowering }\end{array}$ & Jointing and heading & Heading & $\begin{array}{l}\text { Heading and } \\
\text { flowering }\end{array}$ & Jointing and heading \\
\hline & Last & Flowering & $\begin{array}{l}\text { Heading and } \\
\text { flowering }\end{array}$ & $\begin{array}{l}\text { Heading and } \\
\text { flowering }\end{array}$ & Flowering & $\begin{array}{l}\text { Heading and } \\
\text { flowering }\end{array}$ \\
\hline \multirow[t]{3}{*}{ May } & First & Flowering and filling & Flowering & Flowering & Flowering & Flowering \\
\hline & Middle & Filling and maturity & Flowering and filling & Flowering and filling & Flowering and filling & Flowering and filling \\
\hline & Last & Maturity & Flowering and filling & Filling and maturity & Filling and maturity & Filling and maturity \\
\hline \multirow[t]{3}{*}{ June } & First & & Filling and maturity & Filling and maturity & Filling and maturity & Filling and maturity \\
\hline & Middle & & Filling and maturity & Maturity & Maturity & Maturity \\
\hline & Last & & Maturity & & & \\
\hline
\end{tabular}

\subsection{Computation of the Drought Severity Index (DSI)}

Mu et al. (2013) proposed the drought severity index (DSI) based on the NDVI and evapotranspiration computed from remote sensing data. It was corroborated that the DSI performed well in drought monitoring practice in southwestern China (Zhang and Yamaguchi 2014). By exploring the performance of the DSI in northern China, Zhang et al. (2016) found it can accurately reflect drought in this region as well.

Computation of potential evapotranspiration (PET) based on MOD16A2 was done via the Penman-Monteith equation and then ET/PET can be obtained. Computation of the DSI was done by the following procedure: standardization of the NDVI and ET/PET; summation of the standardized NDVI and ET/PET to obtain the $Z$ value; and then standardization of the $Z$ value to obtain the DSI. The algorithms are as follows:

$$
\begin{aligned}
& Z_{\mathrm{ET} / \mathrm{PET}}=\frac{R_{\mathrm{ET} / \mathrm{PET}}-\bar{R}_{\mathrm{ET} / \mathrm{PET}}}{\sigma_{\mathrm{ET} / \mathrm{PET}}} \\
& Z_{\mathrm{NDVI}}=\frac{\mathrm{NDVI}-\overline{\mathrm{NDVI}}}{\sigma_{\mathrm{NDVI}}}
\end{aligned}
$$


$Z=Z_{\mathrm{ET} / \mathrm{PET}}+Z_{\mathrm{NDVI}}$

$\mathrm{DSI}=\frac{Z-\bar{Z}}{\sigma_{Z}}$

where $Z_{\mathrm{ET} / \mathrm{PET}}$ denotes the standardized ET/PET; $R_{\mathrm{ET} / \mathrm{PET}}$ denotes the ET/PET for a certain time interval in a single year during 2001-2016; $\bar{R}_{\mathrm{ET} / \mathrm{PET}}$ denotes the mean ET/PET for the same time interval during the entire 2001-2016 period; $\sigma_{\mathrm{ET} / \mathrm{PET}}$ denotes the standard deviation of ET/PET for the time interval during the 2001-2016 period; $Z_{\mathrm{NDVI}}$ denotes the standardized NDVI; NDVI denotes the NDVI for the same time interval in the same year during 20012016; $\overline{\text { NDVI }}$ denotes the mean NDVI for the time interval during the entire 2001-2016 period; $\sigma_{\mathrm{NDVI}}$ denotes the standard deviation of the NDVI for the time interval during the 2001-2016 period; $\bar{Z}$ denotes the mean $Z$ value for the time interval of the 2001-2016 period; and $\sigma_{Z}$ denotes the standard deviation of the $Z$ value for the time interval during the 2001-2016 period. Mu et al. (2013) proposed the DSI and classified droughts into different drought intensities-the specific classification is shown in Table 2.

\subsection{Detrending of Winter Wheat Yield}

Crop yields are generally composed of trend, climatic fluctuation, and random components. Trend in yields reflects the contribution of factors that affect productivity development while the climatic fluctuation component of yield is the contribution of climate fluctuation, which is mainly associated with meteorological disasters. To investigate the relationship between drought intensity and winter wheat yield, a critical step is to separate the trend from the impact of climatic fluctuation. Therefore, four fitting methods-triple point moving average, exponential smoothing, Logistic, and HP filter-were compared in this study for the separation of trend in yield. The results indicate that the HP filter method has higher accuracy and can be recommended for this study. Therefore, the HP filter method was used for the detrending treatment of winter wheat yield, and the specific calculation algorithm can be found in the relevant literature (Harvey and Trimbur 2008).

Table 2 Drought categories by drought severity index (DSI)

\begin{tabular}{llll}
\hline DSI & Definition & DSI & Definition \\
\hline$\leq-1.5$ & Extreme drought & $0.3-0.59$ & Incipient humidity \\
-1.49 to -1.2 & Severe drought & $0.6-0.89$ & Light humidity \\
-1.19 to -0.9 & Moderate drought & $0.9-1.19$ & Moderate humidity \\
-0.89 to -0.6 & Mild drought & $1.2-1.49$ & Heavy humidity \\
-0.59 to -0.3 & Incipient drought & $\geq 1.5$ & Extreme humidity \\
$-0.29-0.29$ & Normal & &
\end{tabular}

Source: Based on Mu et al. (2013)

\subsection{Correlation Analysis}

The Pearson correlation coefficient is a measure of the linear correlation between two variables (Pearson 1895). According to the DSI values, crop areas affected by droughts of different intensities in each prefecture-level city were extracted, and the correlation coefficient between drought-affected crop area (by drought intensity) and winter wheat yield (detrended) was calculated. The correlation coefficient was used to show the impact of droughts on winter wheat yields in different growth stages.

\section{Results and Discussion}

This study examined the relationship between the DSI and winter wheat yield for prefecture-level cities in five provinces of eastern China in 2001-2016. We first analyzed the spatial and temporal distribution of droughts in the study area. Then the correlation coefficient between drought-affected area and detrended yield of winter wheat was quantified and the impact of droughts of different intensities on winter wheat yield during different growth stages was investigated.

\subsection{Correlations Between the Drought Severity Index (DSI) and Winter Wheat Yield}

Winter wheat yield in the five study provinces is in negative correlation with drought intensities. Lower drought intensities roughly link with higher winter wheat yield. However, decreasing drought intensities do not necessarily imply decreasing frequency of droughts across the study region-severe droughts with short durations can still be observed in smaller areas. Both 2001 and 2002, for example, were characterized by severe droughts in the study region. Based on an 8-day averaged DSI, annual dry spells can be observed during 2001 and 2002 and the winter wheat yield was also lower than the long-term annual average winter wheat yield. Severe drought conditions continued until January-March 2003, followed by shifts between dry and humid conditions thereafter. Winter wheat yield in 2003 was also lower than the long-term annual average. Related studies (Wang et al. 2016, 2018; Zheng et al. 2017) have shown that, although the overall regional drought strength gradually decreased, the frequency of regional and periodic drought significantly increased, and severe droughts in the region often result in crop failure. The period of 2004-2006 witnessed lower intensity and shorter duration droughts and the winter wheat production during that period persistently increased to the long-term annual mean level. From 2007 onwards, with the exception of the 2009 winter season to the summer 
of 2010 and 2011, a positive DSI dominated and the study area was relatively humid. Winter wheat yield also shifted from negative to positive anomalies. Yields were higher than the average and persistently increased from 1 year to another. The period from winter 2009 to summer 2010 was characterized by dry climate conditions and was also the growing season of winter wheat. However, the winter wheat yield in 2010 was slightly increased. Because irrigation was widely practiced in the drought-affected areas, the negative impacts of the droughts were reduced. Figure 2 shows the remarkable correlation or linkages between the DSI and winter wheat yield, and further investigation of the impact of droughts on winter wheat yield during specific critical growth stages will shed light on the mechanism of impact.

\subsection{Temporal Patterns of Droughts of Different Intensities}

The spatiotemporal evolution of droughts with different drought intensities were investigated to evaluate the impact of droughts on crops during specific critical growth stages

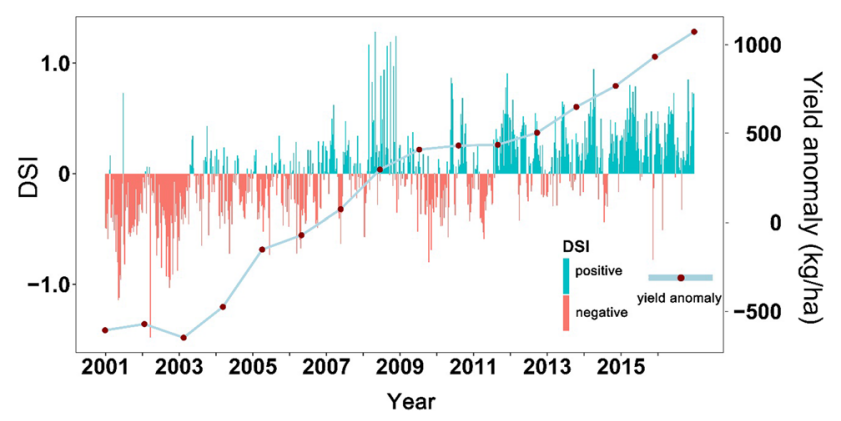

Fig. 2 Comparison between the 8-day average drought severity index (DSI) (columns) and winter wheat yield anomalies (curve) in the study region in eastern China, 2001-2016 and the related impact on winter wheat production. In general, severe to extreme droughts occurred mainly during 2001-2009. Specifically, 2001 and 2003 were dominated by severe and extreme droughts. Droughts occurred mainly in two time periods-March-May and August-October. Consecutive droughts can sometimes be observed during summer and autumn in Anhui, Hebei, Henan, and Shandong Provinces. Few droughts were detected in Jiangsu Province. Higher drought frequency was still observed during 2003-2010. Droughts with lower intensity and lower frequency were observed during 2011-2016 and the study region has tended to be humid in recent years.

Figures 3 and 4 show the seasonal distribution of droughts of different intensities in the five provinces. In general, drought frequency was higher in the spring and autumn seasons, while the frequency of droughts was relatively lower during the summer (particularly in July and August) and winter seasons. Within Anhui Province, droughts occurred mostly during March-June and September-December (Fig. 4a). As many as nine drought events existed on the 57th day of the year during 2001 to 2016 - in more than half of the years. Moderate and severe droughts occurred often in March to April and in September to November. Serious droughts occurred mostly during the spring and autumn seasons. Consecutive drought hazards occurred during both 2001 and 2002 (Fig. 3). In 2001, moderate and severe droughts occurred in April to May, and mid- and late August to mid-October and midNovember; and moderate and severe droughts occurred from mid-September to mid-November in 2002. Generally, autumn is the seeding period for winter wheat and spring is the critical period for the growth and development of winter wheat. Consecutive and long-lasting droughts in those periods can have serious impacts on winter wheat yield.
Fig. 3 Temporal distribution of droughts of different intensities in Anhui, Hebei, Henan, Jiangsu, and Shandong Provinces, China, 2001-2016

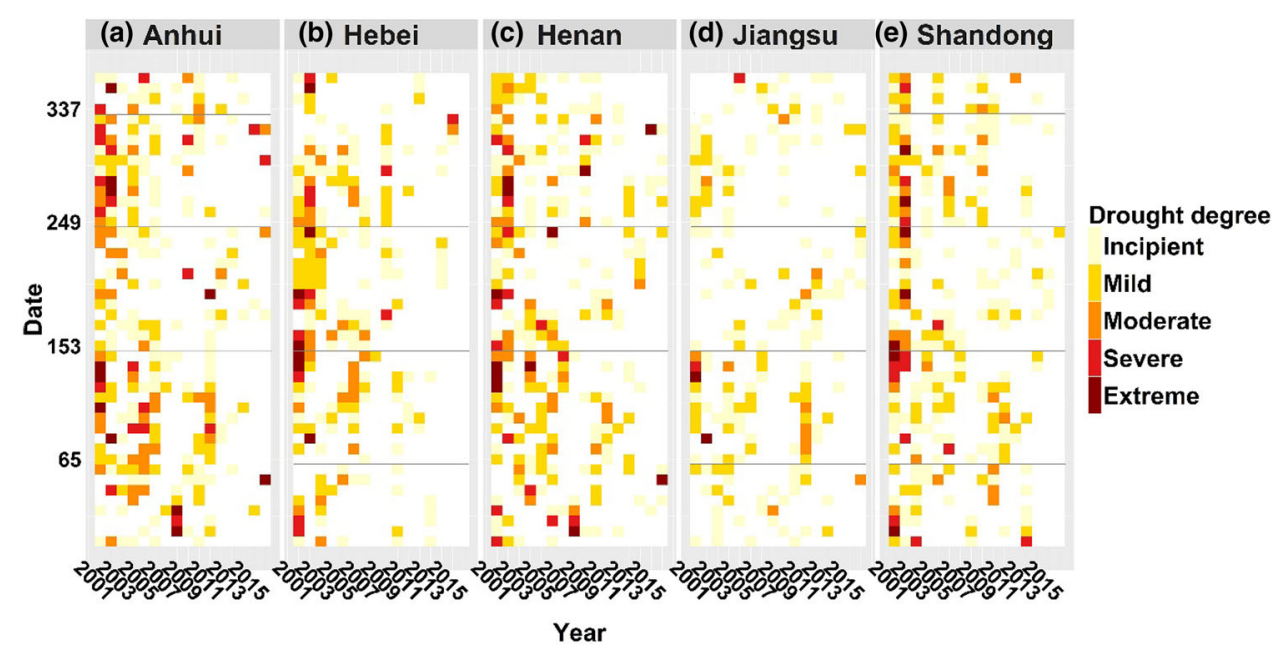



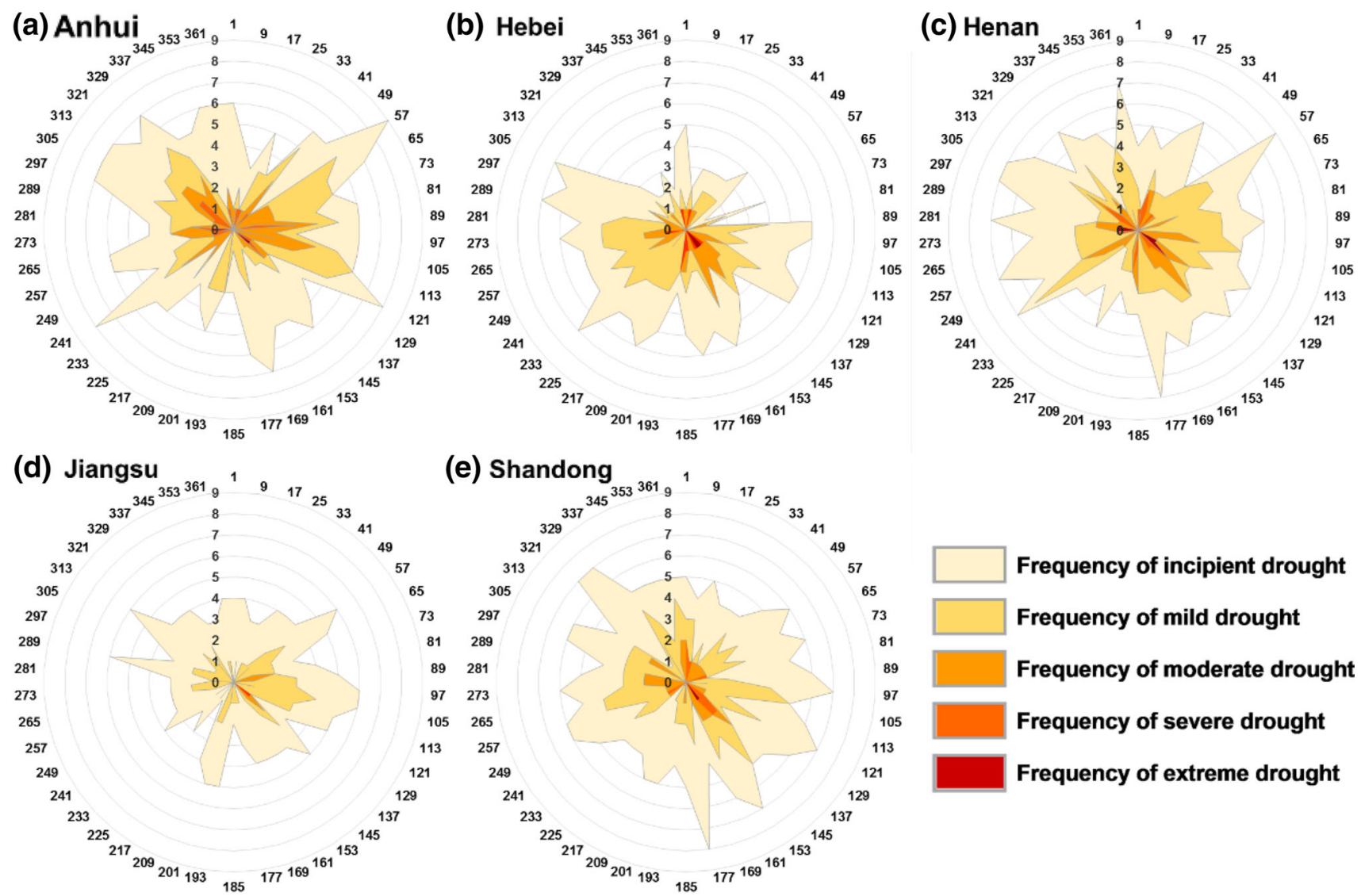

(e) Shandong

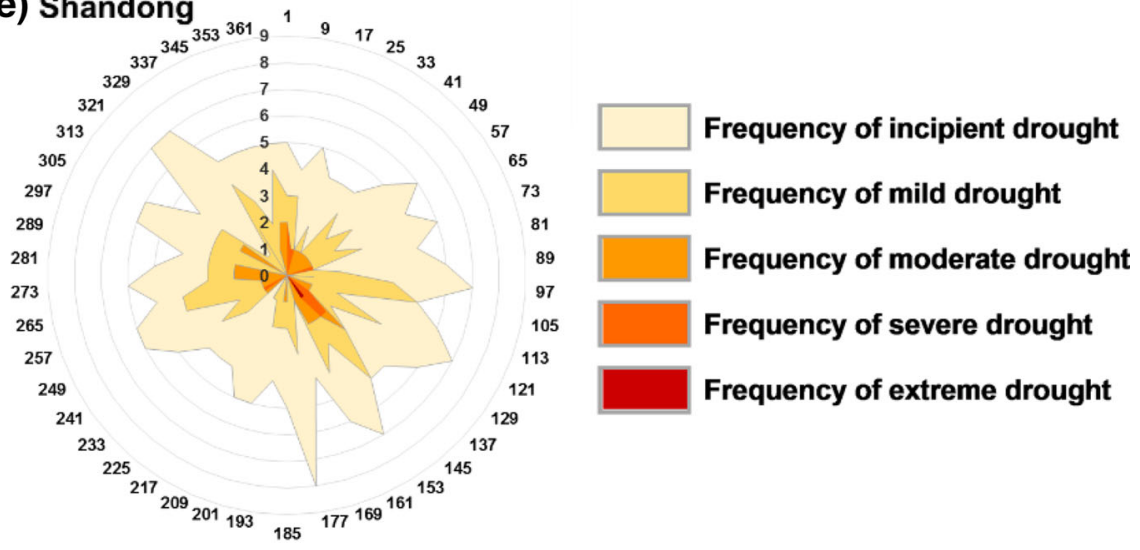

Fig. 4 Temporal distribution of frequency of droughts with different intensities in Anhui, Hebei, Henan, Jiangsu, and Shandong Provinces, China, 2001-2016

A different temporal distribution of droughts within 1 year is observed in Hebei Province compared to that in the other four provinces. Except for the days from November to December and from January to March, a relatively even temporal distribution of drought frequency can be observed (Fig. 4b). During typical drought years, severe consecutive droughts occurred in the spring-summer and autumn-winter seasons-in May-July of 2001 and September-October of 2002 (Fig. 3b). The temporal distribution of droughts within 1 year in Henan Province is similar to that in Anhui Province-droughts occurred mainly during spring and autumn, but relatively high drought frequency and intensity also can be observed in mid-June to July (Fig. 3a, c). The intensity and frequency of droughts in Jiangsu Province are relatively low, mild and incipient droughts are dominant. Droughts occurred mainly during spring - in March to May. The temporal distribution of droughts in Shandong Province is relatively uniform throughout the year and the mean occurrence frequency of incipient droughts ranges from 5 to 6 . However, the differences between Shandong Province and Anhui and Henan Provinces lie in the fact that a lower frequency of moderate, severe, and extreme droughts can be detected in
Shandong Province. A higher frequency of droughts with lower intensity can be observed in Shandong Province when compared to those in Anhui and Henan Provinces (Fig. 4e).

\subsection{Spatial Distribution of Droughts of Different Intensities}

The study region is dominated by a higher frequency of incipient droughts, and 40-50 droughts on average can occur in all seasons (Fig. 5d, h, 1, p), accounting for about $25 \%$ of the total monitored droughts over the 16 years considered in this study. Discernable differences in spatial pattern of moderate and severe droughts can be identified across the study region. A higher occurrence frequency of moderate droughts can be observed in Hebei, Henan, Anhui, central Jiangsu, and eastern Shandong Provinces, and this is particularly true for the occurrence frequency of droughts in northern Hebei, southern Henan, and northern Anhui. The highest frequency of droughts can be detected mainly during spring, with about 30-40 drought events. Severe droughts occurred during the spring, summer, and autumn seasons, mainly concentrated in northern Hebei, 

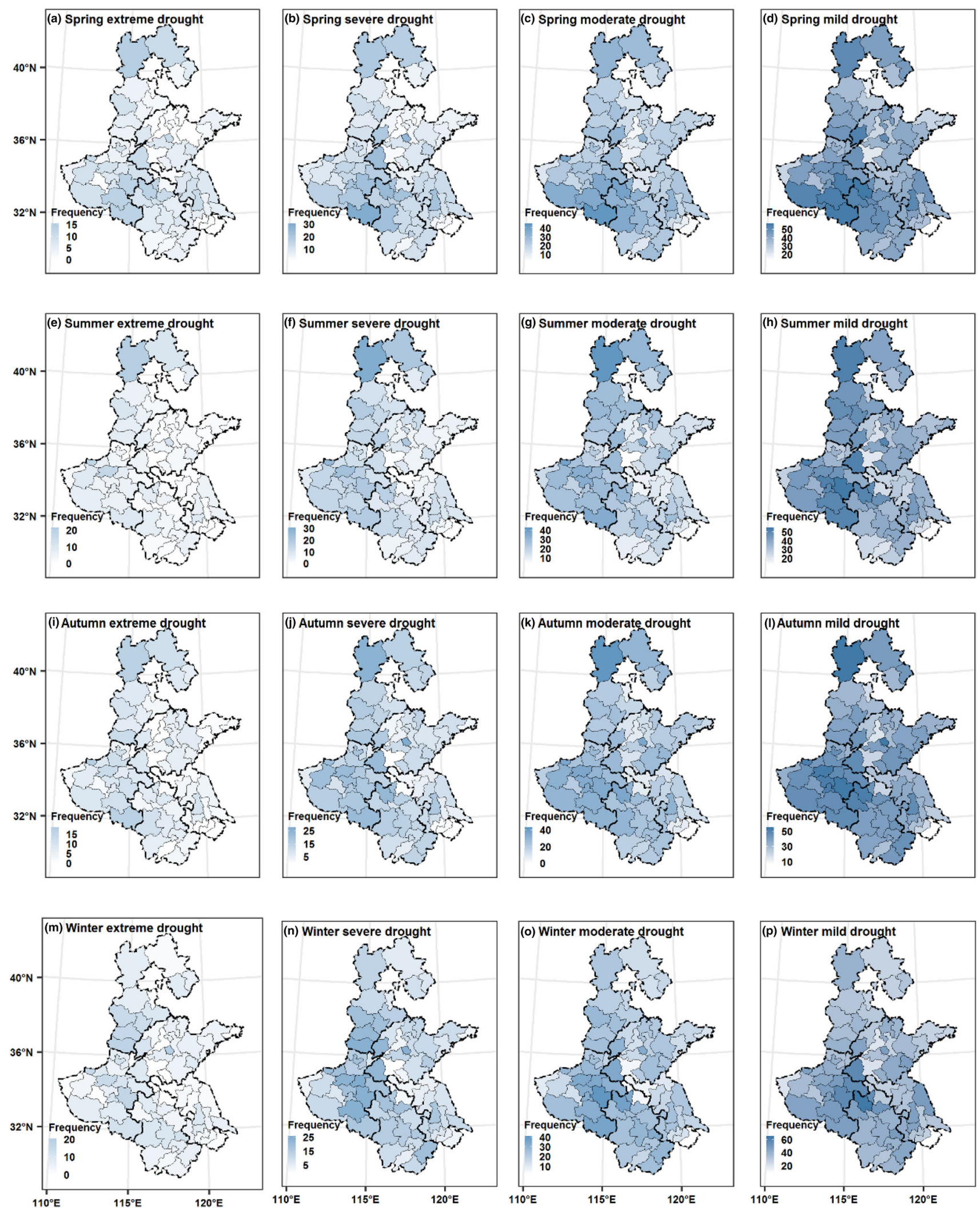

Fig. 5 Spatial distribution of the frequency of droughts of different intensities in Anhui, Hebei, Henan, Jiangsu, and Shandong Provinces, China, 2001-2016 
southeastern Henan, and northern Anhui Provinces, especially in spring. In Hebei Province, droughts occurred in the southern is more serious than the northern part. Regional extreme droughts occurred only about 5-10 times during the study period. Generally, 15-20 extreme drought events can be observed during spring in southern Henan and during winter in northern Hebei.

Except for droughts in winter in Hebei Province, higher frequency of droughts can be detected mainly in the northern part of the study region rather than in the south. In Shandong Province, droughts occurred mainly in the eastern and the central areas. Generally, higher frequency of droughts can be identified across the entire Henan Province. Frequent droughts can be detected in southern Henan, the province's region for winter wheat production, and frequent droughts pose serious challenges for stable production. Overall, droughts in Jiangsu Province are less severe than in the other provinces and occurred mainly in central Jiangsu. In spring and summer, the frequency of droughts in northern Anhui was higher and relatively low in southern Anhui.

\subsection{Impacts of Drought on Crop Yield}

Previous research mainly focused on accurate and real-time monitoring of the occurrence and development of droughts (Aghakouchak et al. 2015), but very few reports addressed the impacts of droughts on growing crops and related crop production. However, droughts with different intensities that occur during different growth stages of crops can have distinctly different impacts on crop yield (Çakir 2004). Therefore, it is critical to investigate the impacts of droughts on winter wheat yield by studying the occurrence timing of droughts relative to the growth stage of winter wheat.

Winter wheat is generally sown in October and harvested in June of the subsequent year. Yield in 1 year is usually affected by the drought conditions in OctoberDecember of the previous year and January-June of the current year. In this study, the correlation between the crop areas affected by droughts of different intensities during January to June of 2002-2016 and the detrended yield of winter wheat in each year from 2002 to 2016 was quantified. The correlation between the crop areas affected by droughts of different intensities during October to December of 2001-2015 and the detrended yield of winter wheat in each year from 2002 to 2016 was also quantified. The correlations were evaluated between crop areas affected by incipient, mild, moderate, severe, and extreme droughts and winter wheat production in order to explore the types of droughts that have the largest impacts on winter wheat production in terms of occurrence timing and intensities (Figs. 6, 7, 8, 9, 10).
Planting of winter wheat across the five provinces generally occurs in early October, and then winter wheat goes through sprouting, tillering, and overwintering. It starts to winter in Hebei and Shandong after mid-December, 10 days earlier than in Henan. But wintering in Jiangsu and Anhui is about 20 days later than in Shandong. This difference in timing of wintering is mainly due to the differences in solar radiation and thermal conditions that vary with latitude. The processes of greening, jointing, heading, flowering, filling, and maturity of winter wheat follow the ending of the winter season. The flowering stage of winter wheat can occur during early April in Jiangsu and Anhui Provinces. But the timing of the flowering stage of winter wheat in Shandong, Henan, and Hebei Provinces is 10-20 days later than in Jiangsu Province.

As shown in Fig. 6, from January to mid-March winter wheat is in the stage of overwintering and green. A weak negative correlation and positive correlation can be identified between incipient drought-affected crop areas and crop yields, implying that incipient droughts during the wintering and greening periods of winter wheat have no significant impacts on winter wheat yields and may even increase the yields of winter wheat slightly. Precipitation and air temperature are the main climatic factors that influence crop growth but they have different impacts on the growing crops in different growth stages. Regardless of the stage of crop growth, changes in cumulative precipitation during the growing season, especially during the earlier growing season, have the greatest impact on winter wheat. A persistent precipitation deficit will potentially have serious cumulative effects on the growth and development of winter wheat, and yield can be greatly reduced. Precipitation in the study region is mainly concentrated in July-September, accounting for about $70 \%$ of the total annual precipitation. Seeding of winter wheat occurs mainly in October. The good soil moisture conditions of the study area in early autumn provide good water conditions for the seeding and overwintering of winter wheat ( $\mathrm{Li}$ et al. 2000). After a long wintering period, winter wheat in the study region enters the green stage. The increase of solar radiation and the warming temperature promote the growth of crops. During this period, under incipient drought conditions, and although winter wheat may suffer some slight water stress, the promotion effect of increased temperature and radiation is dominant in its growth, and these conditions may even increase winter wheat yield. When drought conditions aggravate from moderate to higher intensity (Figs. 8, 9, 10), however, a more serious water deficit will potentially result in a decrease in winter wheat production.

However, negative correlations were detected between incipient droughts and winter wheat yield during early and mid-April (Fig. 6), although these correlations are not 


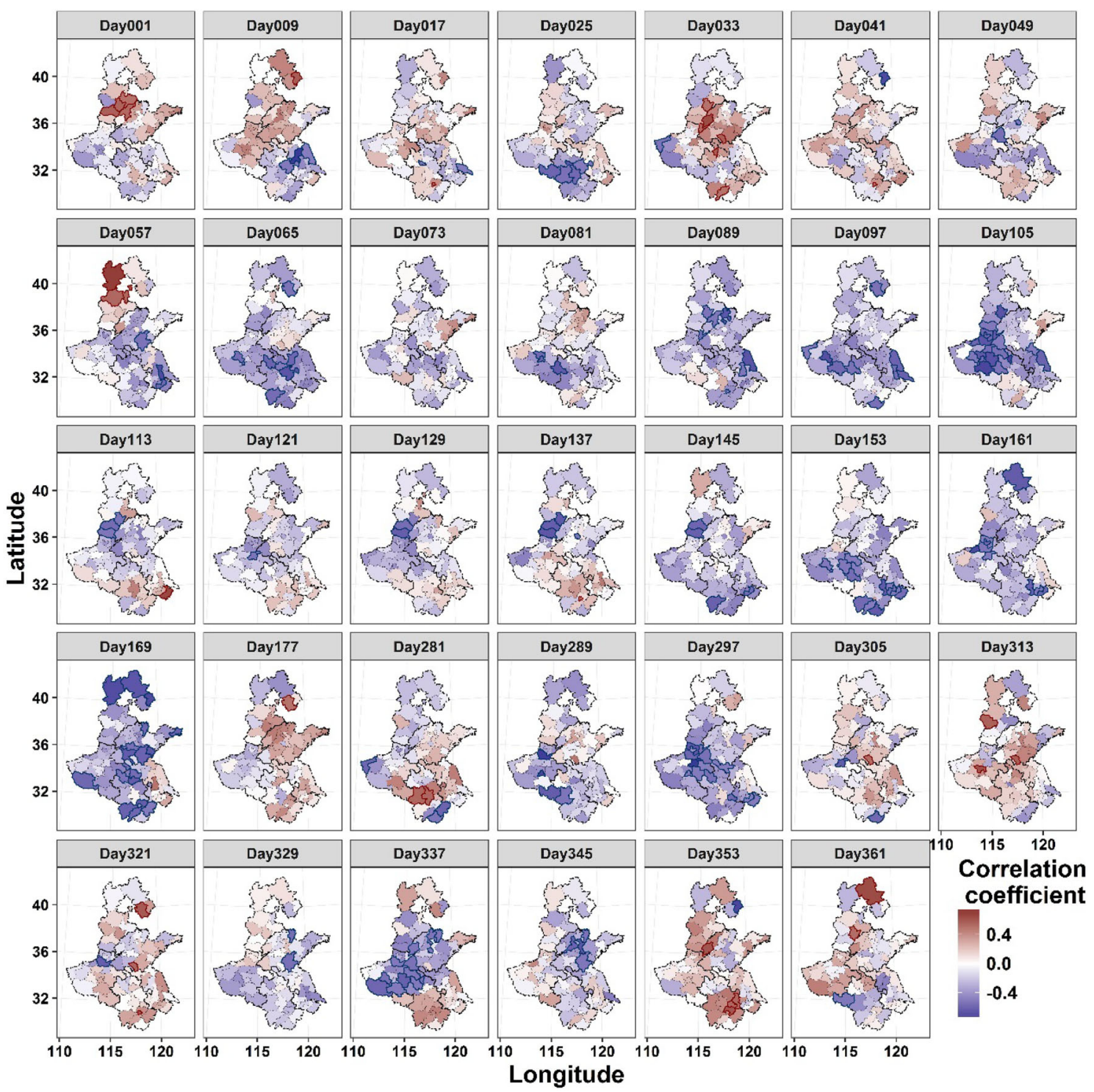

Fig. 6 Spatial pattern of correlations between incipient drought-affected crop area and winter wheat yield in Anhui, Hebei, Henan, Jiangsu, and Shandong Provinces, China, 2001-2016

statistically significant except in southern Henan, Anhui, and northern Jiangsu Provinces. Further analysis indicates that regions dominated by negative correlations are also those dominated by winter wheat entering the stage of heading and flowering, and regions dominated by insignificant correlations are those where winter wheat is entering the jointing and heading periods. Innes and Blackwell (1981) indicated that water stress before flowering of the winter wheat can reduce the number of grains per spike, which can definitely affect the yield of winter wheat. Late May to late June (Day145-Day169 in Fig. 6) witnessed negative correlations between incipient droughts and yield across a larger area of the study region, implying that the incipient droughts that occurred during this period can cause apparent decrease of crop yield—late May to late
June is also the flowering, filling, and maturity stage for winter wheat. Moreover, filling will follow flowering and the duration of filling will impact the fullness of the winter wheat grains (Zhang et al. 1998; Yang and Zhang 2006). The water requirement of winter wheat at this stage increased significantly when compared to that of the previous period. Long drought duration will result in poorer grains of wheat and reduce yield (Fang et al. 2017). A comparison between incipient drought-affected and mild drought-affected crop areas reveals no significant reduction of yield in northeastern Henan, southern Hebei, and central and western Anhui during late May to late June (Day145Day169 in Figs. 6, 7), which can be attributed to the alleviation of droughts as a result of agricultural irrigation in these regions. 


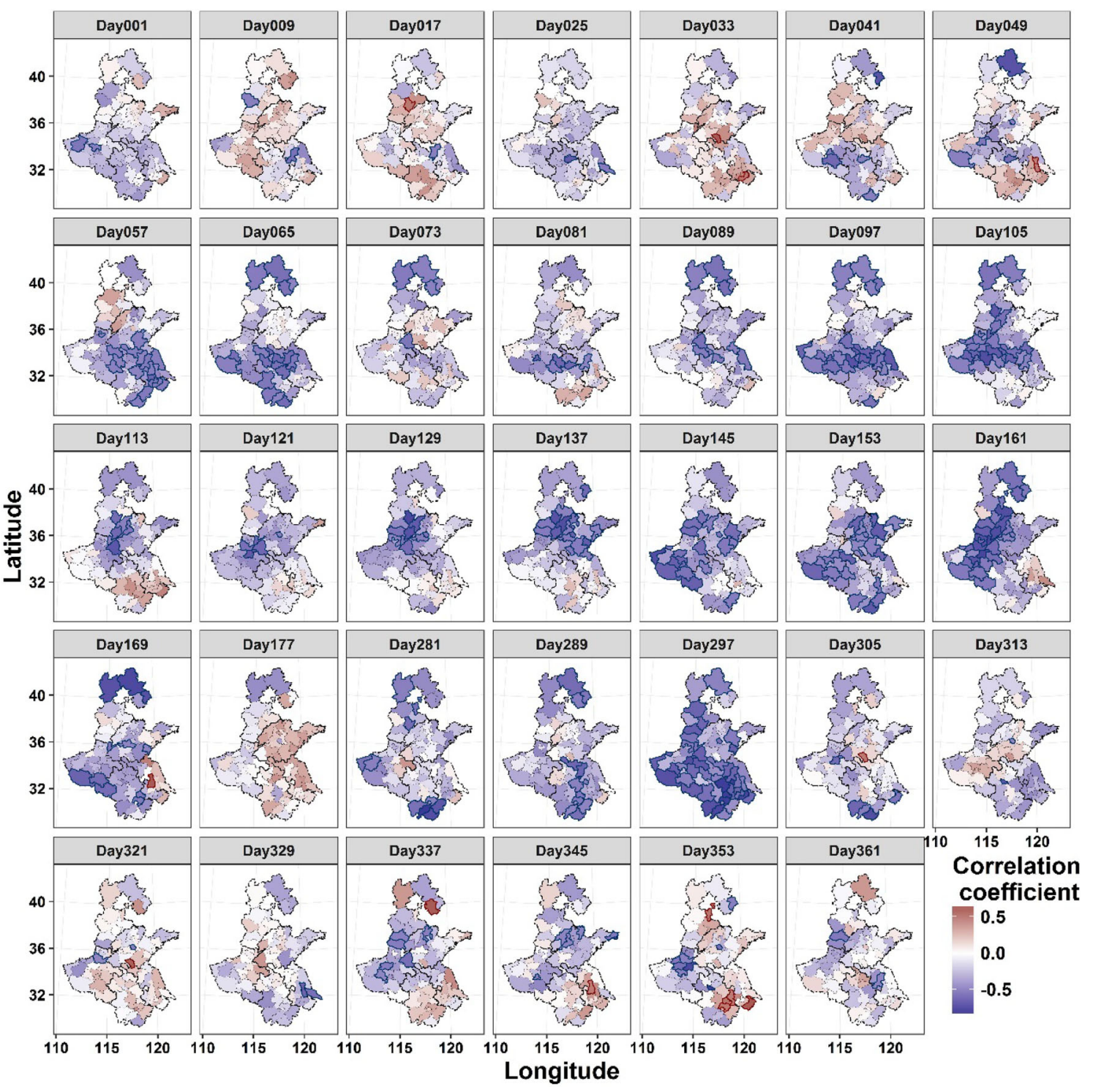

Fig. 7 Spatial pattern of correlations between mild drought-affected crop area and winter wheat yield in Anhui, Hebei, Henan, Jiangsu, and Shandong Provinces, China, 2001-2016

Figure 7 illustrates the correlation between mild drought-affected crop areas and crop yield. No significant correlations can be found during January and February (Day001-Day057 in Fig. 7). When compared with the impacts of incipient droughts on yield, a negative correlation dominates the mild drought-affected crop areas and winter wheat production. Expansion of the mild droughtaffected crop areas links to reduced winter wheat production. Increased intensity of the mild drought largely offsets the positive impacts of increased temperature and solar radiation on the growth of winter wheat. Therefore, water deficit plays a critical role in the growth of winter wheat crops. In early and mid-April (Day097-Day105 in Fig. 7), a wide range of areas in northern Anhui, northwestern Jiangsu, and southern Henan were characterized by negative correlation coefficients and this time period corresponds to jointing and flowering. From late May to midJune (Day137-Day161 in Fig. 7), a negative correlation between yield and mild drought-affected crop areas dominates large areas, and significant negative correlation was found at 0.01 significance level in Henan, Shandong, southern Hebei, and parts of Anhui Provinces. A closer look at these significant correlations indicates that mild drought had a profound impact on the yield of winter wheat during the filling and ripening stage. In the tillering stage of winter wheat growth (Day297), mild droughts still can potentially cause reduction of yield, especially in Anhui, Henan, and southern Hebei Provinces. When compared to the intensity of incipient droughts, the intensity of mild droughts is higher (Figs. 6, 7) and a stronger negative 


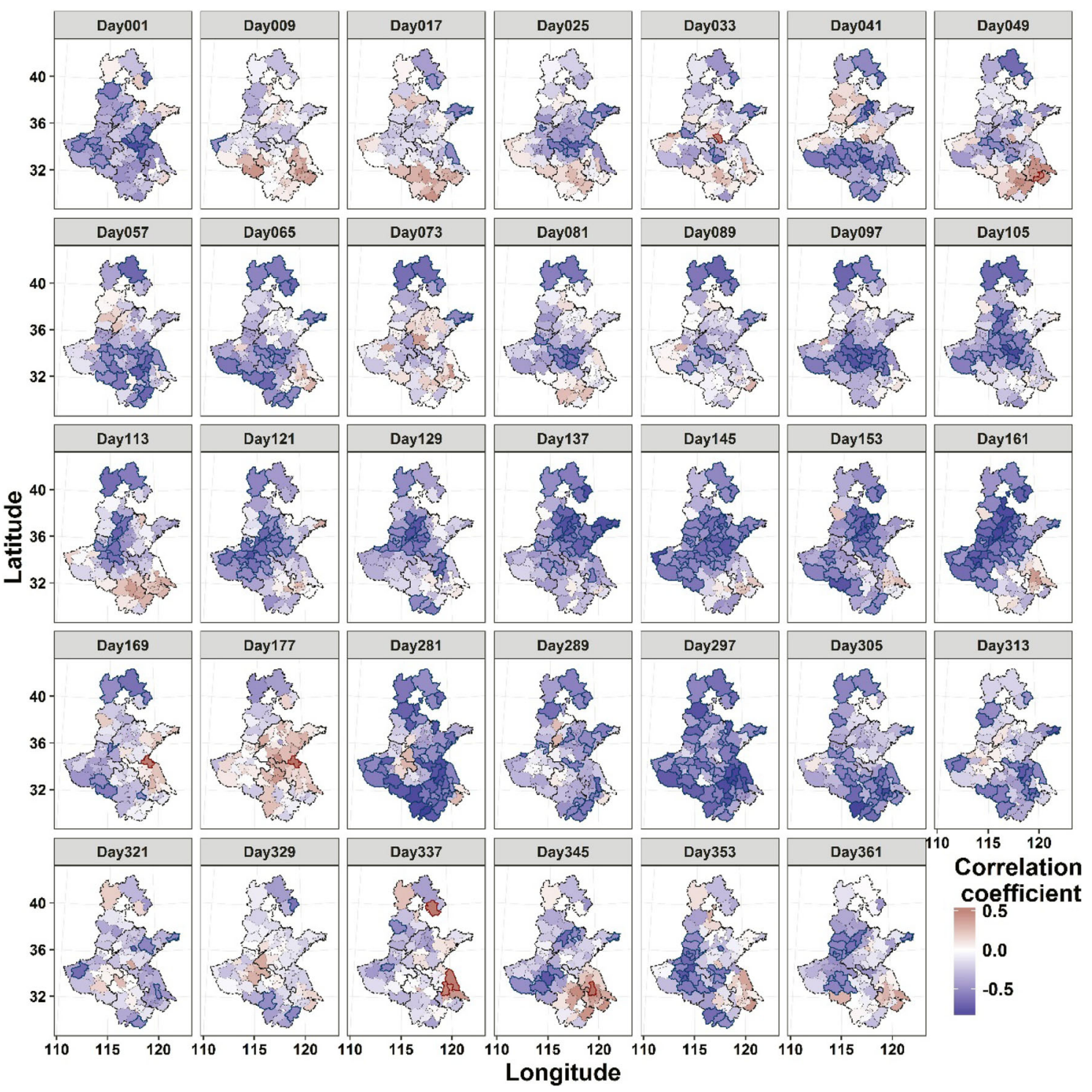

Fig. 8 Spatial pattern of correlations between moderate drought-affected crop area and winter wheat yield in Anhui, Hebei, Henan, Jiangsu, and Shandong Provinces, China, 2001-2016

correlation can be observed between yield and mild drought-affected crop areas, implying that a higher intensity of mild drought will have more effects on winter wheat production, and this is particularly true for winter wheat yield during the greening to maturity periods.

Impacts of moderate droughts on winter wheat yield are similar to those of mild droughts (Figs. 7, 8). The difference is that mild drought during the wintering, greening, and jointing stages of winter wheat growth may have a promoting effect on yield. Moderate droughts have negative impacts on winter wheat yield during this same period and reduce winter wheat production (Zhang et al. 2008). From incipient drought to mild drought and moderate drought (Figs. 6, 7, 8), droughts of higher intensity have more significant impacts on winter wheat at its earlier growing season. For example, incipient drought can have discernable impacts on winter wheat yield during the filling period, while moderate droughts may have remarkable impacts on yield during the flowering, filling, and maturity period. In this sense, the impact of water stress on winter wheat yield is mainly reflected by the long-term cumulative effects (Huang et al. 2016). For severe and extreme droughts, the correlations between drought-affected crop areas and winter wheat production are less significant than those for mild and moderate droughts (Figs. 9, 10). What is particularly noteworthy is that the spatial pattern of severe and extreme droughts is significantly correlated with crop yield in October (Day281-Day297 in Figs. 9, 10), and this is also the time period for seeding and the sprouting stage of the winter wheat. Severe drought events can trigger 


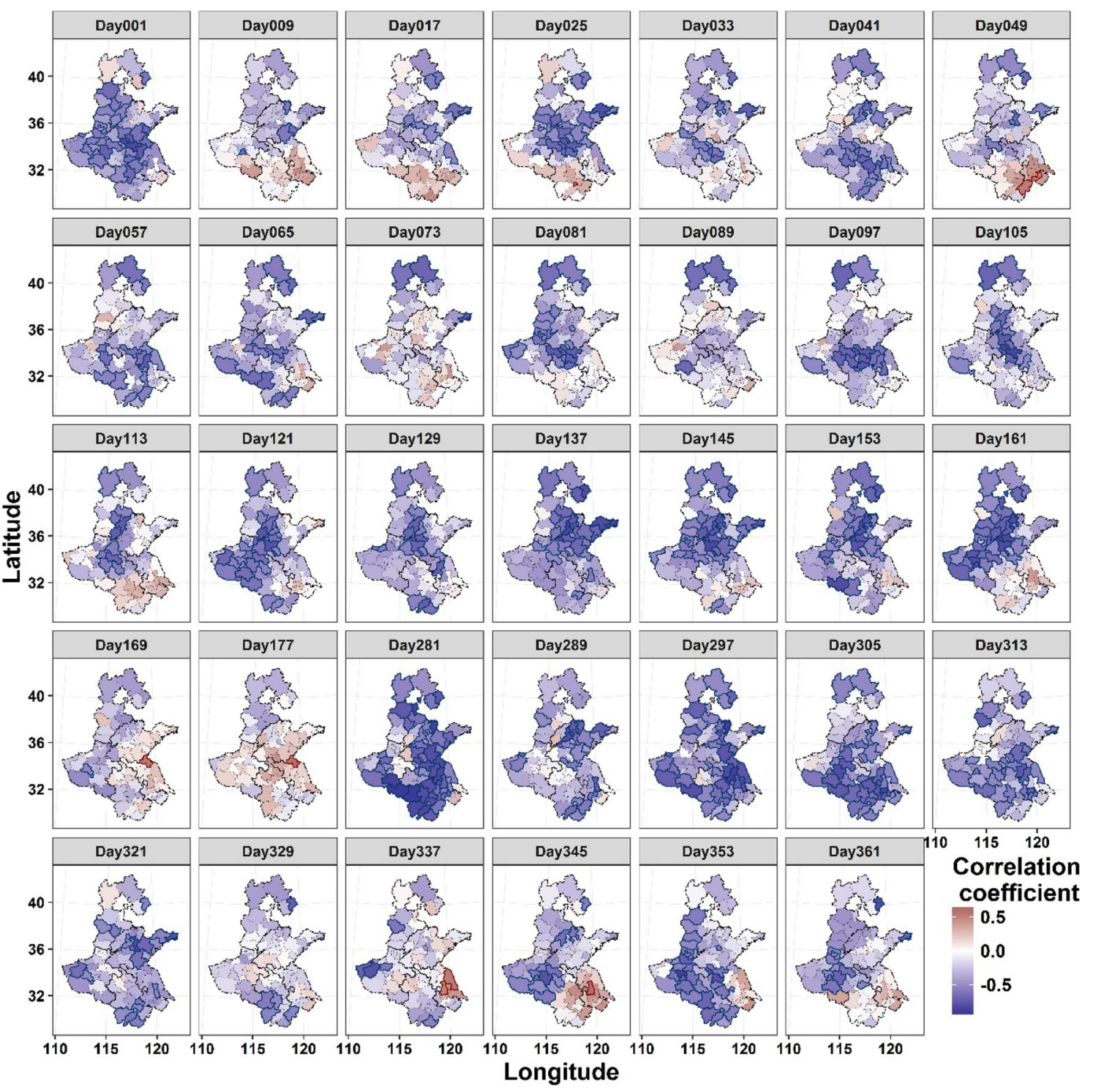

Fig. 9 Spatial pattern of correlations between severe drought-affected crop area and winter wheat yield in Anhui, Hebei, Henan, Jiangsu, and Shandong Provinces, China, 2001-2016

lower sprouting rates of winter wheat and have negative impacts on yield.

These results show that droughts of different intensities occurring in different growth stages have distinct effects. It is unnecessary to irrigate when incipient droughts occur during the wintering and greening periods, but irrigation is indispensable to alleviate droughts when their intensity reaches the moderate level. Flowering and filling stage is the most sensitive period for winter wheat to water, and mild drought will lead to a sharp decline in yield. With the intensity of drought aggravating, the negative effect on winter wheat yield becomes more significant. Therefore, particular attention should be paid to this growing period for drought monitoring and irrigation.

\section{Conclusion}

In this study, the drought severity index (DSI) was applied based on the NDVI and evapotranspiration data at the temporal scale of 8 days. Spatiotemporal patterns of DSIbased droughts of different intensities were investigated, and correlation coefficients between drought-affected crop areas and the detrended yield of winter wheat were calculated and analyzed.

The temporal resolution of data used in calculating the DSI is 8 days, so the index values can reflect the intensity of drought in different growth and development stages of crops. Evapotranspiration and vegetation conditions were both taken into account in calculating the DSI, so the index can better reflect the conditions of crops and be more 


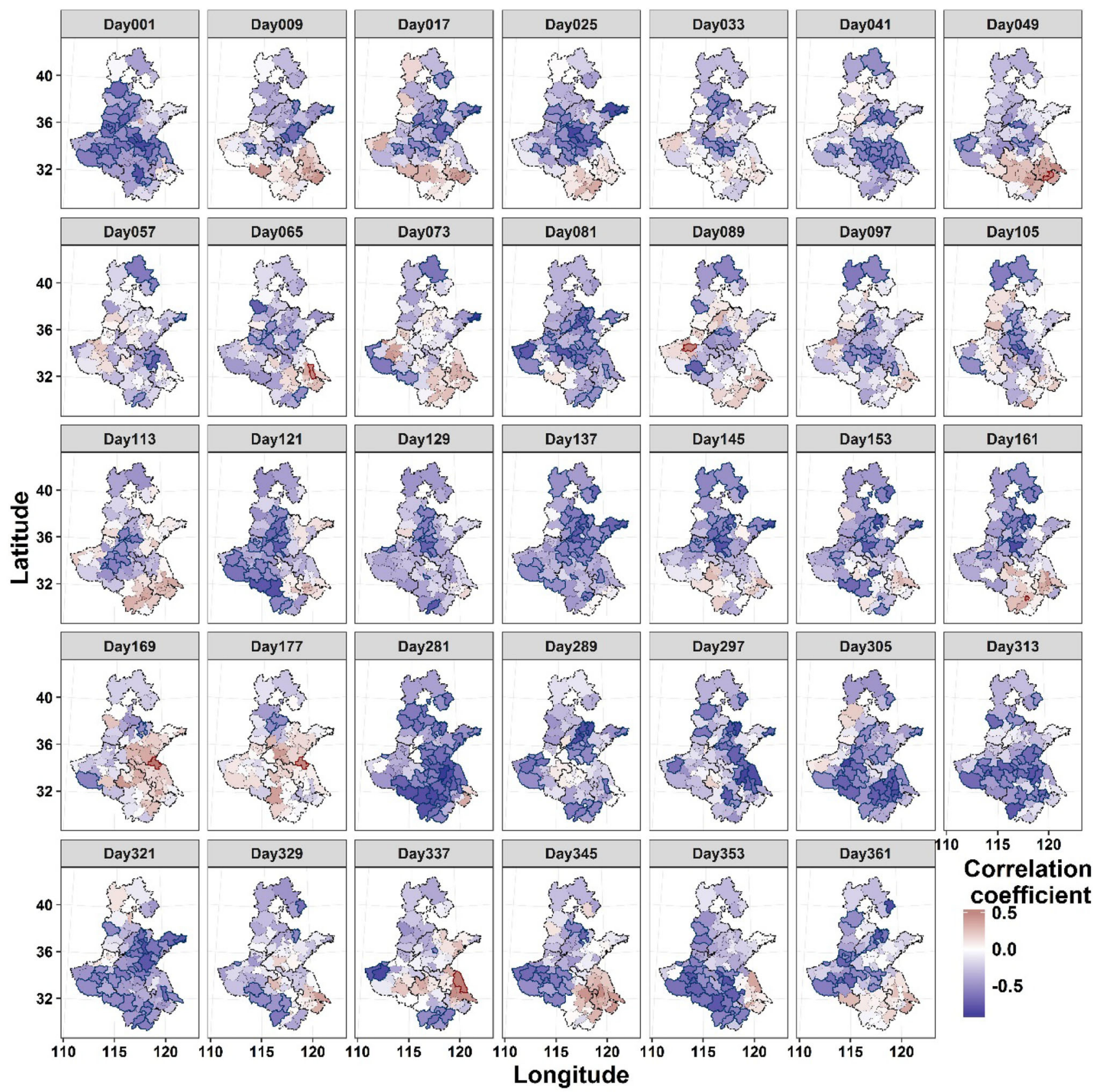

Fig. 10 Spatial pattern of correlations between extreme drought-affected crop area and winter wheat yield in Anhui, Hebei, Henan, Jiangsu, and Shandong Provinces, China, 2001-2016

suitable for the monitoring of agricultural drought. Correlation analysis was done to explore drought effects on winter wheat yield during different growth stages. This is the theoretical basis for irrigation planning during different periods of winter wheat growth. However, the study also has some deficiencies. The limited temporal coverage of the time series data used in calculating the DSI may affect its accuracy in identifying droughts. It is also important to note that the climate change since the 20th century has caused some changes in the frequency and distribution of extreme events, such as drought, and it may be more reasonable to characterize drought relative to the state of recent years. In general, the short time span and insufficient data coverage increase the uncertainty of the conclusions. Moreover, there are a large number of irrigated areas in the study region. Irrigation can alleviate drought conditions and reduce the effect on yield. However, because irrigation time, volume, methods, and other relevant data cannot be obtained, the impact of irrigation on winter wheat yield was not examined in this study. Despite these limits, by 
using the existing data and methods, we have come to the following conclusions:

1. Droughts in 2001-2016 showed a decreasing trend at the interannual scale in terms of frequency and intensity. The 2001-2002 period witnessed longer duration of droughts with widespread drought-affected cropland areas in the study region. Regional and intermittent occurrence of droughts was observed during 2003-2010 and the intensity decreased. During 2011-2016, however, the intensity of drought decreased and drought-affected cropland areas shrunk significantly.

2. The seasonal distribution of droughts indicates that droughts occurred mainly during spring and autumn in Anhui, Henan, and Hebei, while relatively even temporal distribution of droughts can be observed in Shandong Province. Drought intensity in Jiangsu was clearly weaker than in other provinces, and the seasonal variability of droughts was not significant. Spatially, higher frequency of droughts can be observed mainly in northern Hebei, southern Henan, Anhui, central and northern Jiangsu, and eastern Shandong Provinces. These areas are also the key regions of winter wheat production. Frequent droughts will definitely have impacts on winter wheat production.

3. The incipient droughts that occurred during the wintering period of the winter wheat growth helped to increase the winter wheat yield, while the mild droughts that occurred during the maturity stage of winter wheat resulted in a reduction of yield. The mild droughts that occurred during the filling and maturity period had a significant effect on the yield of winter wheat. The moderate droughts that occurred during the flowering, filling, and maturity periods of the winter wheat growth had a significant impact on yield. In addition, the water shortage due to droughts that occurred during the seeding period in autumn also affected the production of winter wheat, and that is particularly true for the severe and extreme droughts that occurred during the seeding period. With some exception of the occurrence of droughts of certain intensities during some specific growth stages of winter wheat, droughts of higher intensities had greater impacts on winter wheat yield during the critical growth stages.

The results of this study may provide some practical reference for the planning of agricultural irrigation with the aim to conserve water resources and maintain winter wheat yield in a warming climate.
Open Access This article is distributed under the terms of the Creative Commons Attribution 4.0 International License (http://crea tivecommons.org/licenses/by/4.0/), which permits unrestricted use, distribution, and reproduction in any medium, provided you give appropriate credit to the original author(s) and the source, provide a link to the Creative Commons license, and indicate if changes were made.

\section{References}

Abduwasit, G., Z.L. Li, Q.M. Qin, Q.X. Tong, J.H. Wang, K. Alimujiang, and L. Zhu. 2007. A method for canopy water content estimation for highly vegetated surfaces-shortwave infrared perpendicular water stress index. Science in China Series D: Earth Sciences 50(9): 1359-1368.

Aghakouchak, A., A. Farahmand, F.S. Melton, J. Teixeira, M.C. Anderson, B.D. Wardlow, and C.R. Hain. 2015. Remote sensing of drought: Progress, challenges and opportunities. Reviews of Geophysics 53(2): 452-480.

Battisti, D.S., and R.L. Naylor. 2009. Historical warnings of future food insecurity with unprecedented seasonal heat. Science 323(5911): 240-244.

Beddington, J.R., M. Asaduzzaman, M.E. Clark, A. Bremauntz, M.D. Guillou, M.M. Jahn, E. Lin, T. Mamo, C. Negra, C.A. Nobre, R.J. Scholes, R. Sharma, N.V. Bo, and J. Wakhungu. 2012. The role for scientists in tackling food insecurity and climate change. Agriculture and Food Security 1(1): 1-10.

Çakir, R. 2004. Effect of water stress at different development stages on vegetative and reproductive growth of corn. Field Crops Research 89(1): 1-16.

Chen, C., E.L. Wang, Q. Yu, and Y.Q. Zhang. 2010. Quantifying the effects of climate trends in the past 43 years (1961-2003) on crop growth and water demand in the North China Plain. Climatic Change 100(3-4): 559-578.

China Meteorological Administration. 2011. China meteorological disaster yearbook 2011. Beijing: China Meteorological Press (in Chinese).

Coumou, D., and S. Rahmstorf. 2012. A decade of weather extremes. Nature Climate Change 2(7): 491-496.

Devereux, S. 2007. The impact of droughts and floods on food security and policy options to alleviate negative effects. Agricultural Economics 37(s1): 47-58.

Douglas, I. 2009. Climate change, flooding and food security in south Asia. Food Security 1(2): 127-136.

Fang, Q., X.Y. Zhang, S.Y. Chen, L.W. Shao, and H.Y. Sun. 2017. Selecting traits to increase winter wheat yield under climate change in the North China Plain. Field Crops Research 207: 30-41.

Farhangfar, S., M. Bannayan, H.R. Khazaei, and M.M. Baygi. 2015. Vulnerability assessment of wheat and maize production affected by drought and climate change. International Journal of Disaster Risk Reduction 13: 37-51.

Ghose, B. 2014. Food security and food self-sufficiency in China, from past to 2050. Food and Energy Security 3(2): 86-95.

Godfray, H.C.J., J. Pretty, S.M. Thomas, E.J. Warham, and J.R. Beddington, 2011. Linking policy on climate and food. Science 331(6020): 1013-1014.

Guo, E.L., X.P. Liu, J.Q. Zhang, Y.F. Wang, C.L. Wang, R. Wang, and D.J. Li. 2017. Assessing spatiotemporal variation of drought and its impact on maize yield in Northeast China. Journal of Hydrology 553: 231-247.

Harvey, A., and T. Trimbur. 2008. Trend estimation and the HodrickPrescott filter. Journal of the Japan Statistical Society 38(1): $41-49$. 
Huang, Q., L.M. Wang, Z.X. Chen, and H. Liu. 2016. Effects of meteorological factors on different grades of winter wheat growth in the Huang-Huai-Hai Plain, China. Journal of Integrative Agriculture 15(11): 2647-2657.

Innes, P., and R.D. Blackwell. 1981. The effect of drought on the water use and yield of two spring wheat genotypes. The Journal of Agricultural Science 96(3): 603-610.

Lesk, C., P. Rowhani, and N. Ramankutty. 2016. Influence of extreme weather disasters on global crop production. Nature 529(7584): 84-96.

Li, F.R., S.L. Zhao, and G.T. Geballe. 2000. Water use patterns and agronomic performance for some cropping systems with and without fallow crops in a semi-arid environment of northwest China. Agriculture Ecosystem Environment 79(2): 129-142.

Li, Q.H., and Y.N. Chen. 2014. Response of spatial and temporal distribution of NDVI to hydrothermal condition variation in arid regions of northwest China during 1981-2006. Journal of Glaciology and Geocryology 36(2): 327-334.

Lobell, D.B., W. Schlenker, and J. Costa-Roberts. 2011. Climate trends and global crop production since 1980. Science 333(6042): 616-620.

McKee, T.B., N.J. Doesken, and J. Kleist. 1993. The relationship of drought frequency and duration to time scales. In Proceedings of the Eighth Conference on Applied Climatology, American Meteorological Society, 17-22 January 1993, Anaheim, California, USA, 179-184.

$\mathrm{Mu}$, Q.Z., M.S. Zhao, J.S. Kimball, N.G. McDowell, and S.W. Running. 2013. A remotely sensed global terrestrial drought severity index. Bulletin of the American Meteorological Society 94(1): 83-98.

MWRC (Ministry of Water Resources of the People's Republic of China). 2011. Bulletin of flood and drought disasters in China 2010. Beijing: China Water \& Power Press (in Chinese).

NBSC (National Bureau of Statistics of the People's Republic of China). 2016. China statistical yearbook. Beijing: China Statistics Press (in Chinese).

Palmer, W.C. Meteorological Drought. 1965. Washington, DC: U.S. Weather Bureau.

Park, S., J. Im, E. Jang, and J. Rhee. 2016. Drought assessment and monitoring through blending of multi-sensor indices using machine learning approaches for different climate regions. Agricultural and Forest Meteorology 216: 157-169.

Pearson, K. 1895. Notes on regression and inheritance in the case of two parents. Proceedings of the Royal Society of London 58: 240-242.

Peters, A.J., E.A. Walter-Shea, L. Ji, A. Vina, M. Hayes, and M.D. Svoboda. 2002. Drought monitoring with NDVI-based standardized vegetation index. Photogrammetric Engineering \& Remote Sensing 68(1): 71-76.

Powell, J.P., and S. Reinhard. 2016. Measuring the effects of extreme weather events on yields. Weather and Climate Extremes 12: 69-79.

Qi, H.X., X.F. Zhi, and Y.Q. Bai. 2011. Interdecadal variation and trend analysis of the drought occurrence frequency in China. Transactions of Atmospheric Sciences 34(4): 447-455.

Qin, Z., H. Tang, W. Li, H. Zhang, S. Zhao, and Q. Wang. 2014. Modelling impact of agro-drought on grain production in China. International Journal of Disaster Risk Reduction 7: 109-121.

Rosenzweig, C., A. Iglesias, X.B. Yang, P.R. Epstein, and E. Chivian. 2001. Climate change and extreme weather events: Implications for food production, plant diseases, and pests. Global Change and Human Health 2(2): 90-104.

Salinger, M.J., C.J. Stigter, and H.P. Das. 2000. Agrometeorological adaptation strategies to increasing climate variability and climate change. Agricultural and Forest Meteorology 103(1): 167-184.
Seneviratne, S.I., N. Nicholls, D. Easterling, C.M. Goodess, and S. Kanae. 2012. Managing the risks of extreme events and disasters to advance climate change adaptation: Changes in climate extremes and their impacts on the natural physical environment. The Journal of Clinical Endocrinology \& Metabolism 18(6): 586-599.

Song, F.Q., K.X. Xing, Y. Liu, Z. Liu, and Z. Kang. 2011. Monitoring and assessment of vegetation variation in northern Shanxi based on MODIS/NDVI. Acta Ecologica Sinica 31(2): 354-363.

Sun, P., Q. Zhang, C. Cheng, V.P. Singh, and P.J. Shi. 2017. ENSOinduced drought hazards and wet spells and related agricultural losses across Anhui Province, China. Natural Hazards 89(2): 963-983.

Sun, P., Q. Zhang, Q.Z. Wen, V.P. Singh, and P.J. Shi. 2017. Multisource data based integrated agricultural drought monitoring in the Huai River basin, China. Journal of Geophysical Research 122: 10751-10772.

Vicente-Serrano, S.M., S. Begueria, J.I. Lopez-Moreno, and A.E. Kenawy. 2010. A multi-scalar drought index sensitive to global warming: The standardized precipitation evapotranspiration index. Journal of Climate 23(7): 1696-1718.

Wang, H.S., S.M. Vicente-serrano, F.L. Tao, X.D. Zhang, P.X. Wang, C. Zhang, Y.Y. Chen, D.H. Zhu, and A.E. Kenawy. 2016. Monitoring winter wheat drought threat in northern China using multiple climate-based drought indices and soil moisture during 2000-2013. Agricultural and Forest Meteorology 228-229: 1-12.

Wang, S.S., X.G. Mo, S. Hu, S.X. Liu, and Z.J. Liu. 2018. Assessment of droughts and wheat yield loss on the North China Plain with an aggregate drought index (ADI) approach. Ecological Indicators 87: 107-116.

Yang, J.C., and J.H. Zhang. 2006. Grain filling of cereals under soil drying. New Phytologist 169(2): 223-236.

Zhang, J.H., X.Z. Sui, B. Li, B.L. Su, J.M. Li, and D.X. Zhou. 1998. An improved water-use effciency for winter wheat grown under reduced irrigation. Field Crops Research 59(2): 91-98.

Zhang, Q., X.H. Gu, V.P. Singh, D.D. Kong, and X.H. Chen. 2015. Spatiotemporal behavior of floods and droughts and their impacts on agriculture in China. Global and Planetary Change 131: 63-72.

Zhang, Q., P. Sun, J.F. Li, V.P. Singh, and J.Y. Liu. 2015. Spatiotemporal properties of droughts and related impacts on agriculture in Xinjiang, China. International Journal of Climatology 35(7): 1254-1266.

Zhang, Q., Q. Li, V.P. Singh, P.J. Shi, Q.Z. Huang, and P. Sun. 2018. Nonparametric integrated agrometeorological drought monitoring: Model development and application. Journal of Geophysical Research 123: 73-88.

Zhang, Q., Y. Wang, V.P. Singh, X.H. Gu, and D.D. Kong. 2016. Impacts of ENSO and ENSO Modoki + A regimes on seasonal precipitation variations and possible underlying causes in the Huai River basin, China. Journal of Hydrology 533: 308-319.

Zhang, X.Q., and Y. Yamaguchi. 2014. Characterization and evaluation of MODIS-derived drought severity index (DSI) for monitoring the 2009/2010 drought over southwestern China. Natural Hazards 74(3): 2129-2145.

Zhang, X.Y., S.Y. Chen, H.Y. Sun, P. Dong, and Y.M. Wang. 2008. Dry matter, harvest index, grain yield and water use efficiency as affected by water supply in winter wheat. Irrigation Science 27(1): 1-10.

Zhao, W.L., Z. He, J.P. He, and L.Q. Zhu. 2012. Remote sensing estimation for winter wheat yield in Henan based on the MODISNDVI data. Geographical Research 31(12): 2310-2320.

Zheng, C.Y., J. Zhang, J. Chen, C.Q. Chen, Y.L. Tian, A.X. Deng, Z.W. Song, M.M. Nawaz, K.J. Groenigen, and W.J. Zhang. 2017. Nighttime warming increases winter-sown wheat yield across major Chinese cropping regions. Field Crops Research 214: 202-210. 